\title{
La salud y enfermedad de los líderes como variable estratégica en la comunicación política y electoral
}

\section{Leader's Health and disease as a strategic variable in political and electoral communication}

Roberto Rodríguez Andrés. Universidad Pontificia Comillas ICAI-ICADE y Universidad de Navarra

Recibido: 06-VII-2012 - Aceptado: 22-I-2013

Resumen:

Desde las disciplinas de la Historia, las Ciencias Políticas o la Medicina llevan años investigando acerca de las enfermedades que han padecido los principales líderes políticos del mundo y cómo han podido afectar a sus decisiones. Pero esta cuestión incumbe no sólo al terreno de la gestión sino que tiene también importantes repercusiones en el ámbito de la comunicación política y electoral. En este artículo se analizará cómo los asesores intentan aprovechar la salud de sus líderes para proyectar una imagen dinámica de ellos y, al tiempo, cómo deben afrontar desde el punto de vista de la comunicación el hecho de que se vean afectados por una enfermedad, intentando que esas posibles dolencias no menoscaben su valoración popular y que ésta pueda incluso salir reforzada.

Palabras clave:

Comunicación política, campañas electorales, liderazgo, salud, enfermedad.

Abstract:

Disciplines like History, Political Science or Medicine have being investigating for years the diseases that main political leaders around the world have endured and how these might have conditioned their decisions. But this situation involves not only the field of management; it also has important consequences in the sphere of political and electoral communication. In this article we will analyse how consultants try to take advantage of their leaders' health to show a dynamic picture of them and how they have to confront, in terms of communications, the fact that they are affected by a sickness, trying that those malaises do not to affect their popularity and even be reinforced.

Keywords:

Political communication, electoral campaigns, leadership, health, disease. 


\section{Introducción}

La publicación en 2009 del libro En el poder y en la enfermedad, escrito por el médico y político británico David Owen, sirvió para poner de actualidad cómo el estado de salud y, sobre todo, las posibles enfermedades de los principales líderes políticos de la última centuria, han podido condicionar el devenir de sus decisiones y, en definitiva, el futuro de sus naciones y de toda la humanidad (Owen, 2010).

Pero la reflexión sobre la salud de los gobernantes no se ciñe sólo al ámbito de sus acciones de gobierno. También tiene una dimensión pública porque, con frecuencia, las noticias sobre posibles achaques de los líderes aparecen en los medios de comunicación, unas veces confirmadas por los propios interesados y, en otras ocasiones, en forma de rumores, informaciones confusas o desmentidos oficiales. En definitiva, la salud de los gobernantes, o de quienes aspiran a serlo, es un tema que despierta cada vez más interés entre los periodistas (Annas, 1995; Lehman-Wilzig, 2003). Incluso hay quien se atreve a afirmar, como el corresponsal político de Time y la NBC, Tom Curry (2008), que este asunto, en determinados momentos, puede decidir el resultado de unas elecciones.

Y precisamente por ello ha acabado convirtiéndose en un factor estratégico más para quienes trabajan en el ámbito de la comunicación política, que deben planificar las consecuencias que puede acarrear la salud de sus superiores en su imagen pública o en la de las instituciones que representan, tanto en el transcurso de las legislaturas como durante una campaña electoral.

En definitiva, ¿̇cómo se comunica en política el buen estado de salud de los líderes o sus posibles dolencias? ¿Qué importancia estratégica tiene este factor (netamente personal) sobre la comunicación institucional de un partido o un gobierno? En el presente artículo se analizarán estas cuestiones, basándonos en la revisión de la bibliografía existente hasta el momento y la observación de casos prácticos en distintos países del mundo, abordando dos asuntos fundamentales. En primer lugar, la incidencia de la buena salud de los políticos en su valoración popular y cómo los asesores, conocedores de este extremo, tratan de subrayar este aspecto como uno de los puntos fuertes de sus líderes en términos de comunicación hacia la opinión pública. Y, en segundo lugar, y en el lado opuesto, cómo influye la enfermedad en esa imagen de los políticos, cómo ésta puede trascender e influir sobre la política comunicativa de la institución o partido que representan y cómo se suele actuar ante estos casos, pasando desde la negación u ocultación de la dolencia hasta su reconocimiento público, con las implicaciones que una u otra forma de obrar tienen en términos de comunicación.

\section{Mostrar la buena salud de los líderes como factor estratégico en la comunicación política}

En la comunicación política moderna, sobre todo desde la irrupción del medio televisivo, se considera que un líder debe poseer no sólo cualidades técnicas y preparación intelectual sino también características a nivel personal que le hagan re- 
sultar más atractivo de cara al electorado. Y así, se habla de la importancia del carisma, la imagen, la telegenia, el mostrarse como una persona cercana y accesible o de los sentimientos y empatía que sepan trasladar a los ciudadanos en su forma de hablar o actuar (Rees, 1992; Hart, 1994; Berrocal, 2003).

Y en este contexto de "personalización" y "humanización" de la política, en el que la figura del líder adquiere una dimensión estratégica, uno de los aspectos que es cada vez más valorado es su buen estado de salud, asociado muchas veces a la demostración de resistencia y fortaleza física para poder desempeñar correctamente el cargo incluso en los momentos más duros y de mayor tensión. Como afirma Muñoz Alonso, "la personalización de la política ha dado una importancia excepcional a la salud de los gobernantes o de quienes aspiran a serlo (...). Cualquier duda o sospecha en este terreno puede dar al traste con una prometedora carrera política" (1989: 75).

Y para trasladar esta imagen, tan importante hoy día en la comunicación política, los responsables de Comunicación de las instituciones suelen recurrir a dos prácticas: certificar su buena salud a través de la difusión de reconocimientos médicos y dar visibilidad a las buenas prácticas y hábitos saludables de vida que lleven a cabo.

\section{1. "Certificar" la buena salud de los líderes}

En Estados Unidos suele ser habitual que los presidentes se sometan a chequeos médicos anuales, cuyos resultados son difundidos a la prensa para mostrar su buen estado de salud. No es una obligación legal, pero sí se ha convertido en una regla y, a este respecto, algunos autores consideran que estas valoraciones médicas independientes deberían generalizarse (Owen, 2010). En España, por ejemplo, el Rey pasa anualmente este tipo de reconocimientos, a los que desde hace unos años se da publicidad desde la Oficina de Prensa de la Casa Real, pero no los presidentes del gobierno. En Francia, Giscard D’Estaing fue el primer jefe de Estado del país que se comprometió a publicar dos veces al año sus exámenes médicos (aunque no lo cumplió), una tradición que se mantuvo hasta Chirac, que se negó a dar a conocer sus revisiones ( $L a$ Razón, 4 de septiembre de 2005). Esta costumbre volvería a ser retomada por Sarkozy. De hecho, una de las primeras medidas que adoptó al llegar al Elíseo fue someterse a un exhaustivo chequeo en el que fue declarado "apto" para el ejercicio presidencial (El Mundo, 10 de enero de 2008).

También es frecuente que los políticos se pongan en manos de profesionales sanitarios para conocer su estado de salud y sus condiciones físicas cuando tienen que enfrentarse a una campaña. En estos casos no suele ser habitual que se publiquen los resultados, salvo que interese por algún motivo concreto en el marco de la estrategia electoral, como ocurre con aquellos candidatos cuya salud puede acabar convirtiéndose en un punto débil. Esto pasa, por ejemplo, con quienes tienen edad avanzada, que han de justificar ante la opinión pública que, a pesar de los años, gozan de buena salud como para desempeñar el cargo (Rodríguez Andrés, 2013). Este fue el caso de los republicanos Robert Dole en la campaña estadounidense de 1996 y John McCain en la de 2008, en la que, si se hubiera alzado con la victoria, se habría convertido en el 
político con más edad en llegar a la Casa Blanca (72 años). Durante la campaña hubo varios sondeos en los que los ciudadanos consideraban a McCain demasiado mayor, algo que fue aprovechado por los demócratas para erosionar su imagen. Por todo ello, su equipo difundió su historial médico de los últimos años, una colección de más de 1.200 páginas que certificaban que se encontraba en perfecto estado y que, incluso, su condición física no se correspondía con la de alguien de su edad sino mucho más joven (Johnson, 2009).

Pero además de los certificados médicos, los candidatos mayores suelen también hacer valer su buena salud a través de la demostración pública de su capacidad de resistencia. En el año 2004, por ejemplo, el servicio de prensa del presidente de Galicia, Manuel Fraga, divulgó que en los últimos doce meses éste había acudido a 875 actos públicos, recorrido 48.000 kilómetros, estado 33 fines de semana en activo y concedido 420 audiencias públicas. Y todo con 82 años. Se preparaban ya para demostrar que, a pesar de la edad, Fraga estaba en forma para afrontar una nueva campaña electoral, que se celebró en 2005, y en la que la posible fragilidad del político fue uno de los temas más debatidos entre periodistas y políticos (El País, 11 de septiembre de 2011).

Esta estrategia de mostrar a los políticos como "superhombres", capaces de resistir agendas titánicas y horas y horas de trabajo casi sin dormir, y sin desfallecer, es algo que está generalizándose también en los últimos años en las estrategias de comunicación de los gobiernos. Y ello porque, como afirma Arroyo, el pueblo adora a los líderes "aparentemente hiperactivos" (2012: 374). Así, es frecuente encontrar noticias en los medios sobre la capacidad de resistencia de los líderes en cumbres o negociaciones de vital importancia para los países que presiden o difundir cómo son capaces de aguantar jornadas maratonianas de trabajo, siendo los primeros en llegar y los últimos en irse, con el objetivo de trasladar a la opinión pública una imagen de fortaleza, resistencia y sacrificio que es bien valorada y que responde a lo que la ciudadanía puede llegar a exigir de sus gobernantes precisamente en una época en la que crecen los índices de desafección hacia ellos.

\subsection{Difundir los hábitos saludables de vida de los políticos}

Pero además de "certificar" el buen estado de salud de los líderes, es también una práctica frecuente en el ámbito de la comunicación política el mostrarles adoptando hábitos saludables de vida. Llevar una alimentación equilibrada y saludable, hacer ejercicio físico de forma regular y desterrar el consumo de tabaco o alcohol son cuestiones que hoy se tienen en cuenta a la hora de "perfilar" y "humanizar" la imagen pública de los políticos.

Y bien sea por convicción personal, porque se ven obligados a ser consecuentes con lo que legislan y dar ejemplo o porque acaban sucumbiendo a los consejos de sus asesores, muchos son los políticos que dan visibilidad a todos estos aspectos, utilizándolos como parte de su estrategia de comunicación, especialmente durante las campañas. 
Es muy común, por ejemplo, ver a políticos que convocan a los medios para que les fotografíen o graben mientras practican deporte (Chrisafis, 2007). Y es que, como recuerda Martín Salgado (2002), que aparezcan ante los ciudadanos haciendo ejercicio contribuye a darles una imagen de "dinamismo" que es bien valorada por el electorado o, en palabras de Berrocal, les ayuda a "demostrar su energía y vigor" (2004: 62). Además, este tipo de actos sirve también, como ha subrayado Canel (2006), en la estrategia de personificación de las instituciones, que consigue hacerlas más cercanas a los ciudadanos mediante la exhibición pública de las aficiones y cualidades personales de quienes las dirigen. En definitiva, como resume Muñoz Alonso, hoy día los líderes deben proyectar una imagen que "rebose salud, fuerza, capacidad de trabajo y resistencia deportiva" (1989: 76).

En el caso de Estados Unidos, una rápida búsqueda de fotos a través de Internet facilita numerosas instantáneas de líderes como Clinton, Bush u Obama haciendo footing, jugando al baloncesto o al golf. Y lo mismo ocurre en España con Aznar, Zapatero o Rajoy, a quienes hemos podido ver también corriendo, jugando al pádel o montando en bicicleta, en el Reino Unido con Blair y Cameron, en Rusia con Vladimir Putin o en Francia con Sarkozy, Hollande y, años antes, con Giscard d'Estaing, que fue uno de los primeros políticos en Europa en explotar mediáticamente este aspecto. Schwartzenberg (1978) hace alusión a cómo éste solía aparecer con frecuencia en televisión practicando deportes como el esquí, el tenis o el fútbol y, en más de una ocasión, compareció ante los periodistas en los vestuarios con ropa deportiva o incluso con el torso desnudo para responder a sus preguntas.

A este respecto, no hay que olvidar que este tipo de instantáneas son también del gusto de los medios de comunicación, lo que sin duda aumenta su repercusión pública. En un momento en el que los expertos vienen hablando desde hace años del nacimiento de un nuevo género periodístico denominado "info-entretenimiento", en el que en los medios (sobre todo en la televisión) prima más lo interesante que lo importante, y en el que las imágenes extemporáneas, curiosas o anecdóticas acaban copando los informativos y periódicos de todo el mundo, este tipo de noticias sobre políticos practicando deporte suelen encontrar importante eco mediático. En noviembre de 2010, por ejemplo, todos los diarios españoles llevaban a portada una fotografía del presidente español Rodríguez Zapatero haciendo footing con el primer ministro británico David Cameron en la cumbre del G-20 en Seúl, unas imágenes que concitaron también la atención de las cadenas de televisión y que, de hecho, acabaron siendo más relevantes y comentadas en términos mediáticos que los asuntos tratados en esa cumbre.

También es común que desde los gabinetes de prensa gubernamentales se dé a conocer a los medios que un determinado político ha decidido dejar el tabaco, como ocurrió con Obama en diciembre de 2010, cuando el portavoz de la Casa Blanca, Robert Gibbs, confirmó que el presidente llevaba ya nueve meses sin fumar (El Mundo, 10 de diciembre de 2010). En estos casos, se intenta proyectar la imagen de superación y lucha por parte del político para sobreponerse a la adicción. De hecho, el propio Gibbs dijo en rueda de prensa que, en momentos de gran tensión política vividos en esos nueve meses, 
el presidente "habría podido reconfortarse con un cigarrillo, pero luchó contra ese deseo, como millones de americanos". Y en el caso de los políticos que siguen fumando, lo normal es que, casi como norma de protocolo, procuren no hacerlo cuando hay cámaras delante, al ser conscientes de que este hábito está cada vez peor visto socialmente.

Suele ser también recurrente que los políticos, y más quienes están en el gobierno, den ejemplo acerca de comportamientos saludables o solidarios para despertar entre la población esos mismos sentimientos, algo en lo que suelen participar también activamente las primeras damas, como ha ocurrido con Michelle Obama en la lucha contra la obesidad infantil. Y ya no sólo hablamos de buenos hábitos de vida, sino de cuestiones como donar sangre, hacerse chequeos periódicos, vacunarse contra la gripe o prácticas mucho más sorprendentes, como la que se produjo en Zimbawe en agosto de 2011, cuando se anunció que todos los ministros serían circuncidados para dar ejemplo en la lucha contra el SIDA ( $L a$ Vanguardia, 28 de agosto de 2011).

\subsection{La discordancia entre la imagen saludable proyectada y la salud real de los políticos: la ruptura del principio de ejemplaridad}

Pero una cosa es que los políticos aparezcan fomentado hábitos saludables de vida ante los medios y otra bien distinta que esa imagen planificada por sus asesores para darles una impronta de dinamismo se corresponda con la realidad.

En este campo, los periodistas y también los propios partidos rivales escudriñan en el pasado de los políticos intentando encontrar comportamientos contrarios a estos hábitos con los que hacer crítica o una campaña negativa (Mark, 2009). George W. Bush es un claro ejemplo de ello. Durante las dos campañas electorales en las que compitió por la presidencia de Estados Unidos (2000 y 2004) fueron frecuentes las noticias acerca de su afición al alcohol durante determinadas épocas de su vida (Denton, 2002 y 2005). En ese mismo país, Bill Clinton también fue criticado por haber fumado marihuana en su juventud y, durante sus años en el cargo, la oposición sacó a relucir en más de una ocasión la mala dieta alimenticia del presidente, aficionado en exceso a las hamburguesas y la comida rápida (Rodríguez Andrés y Ruiz de Galarreta, 1996), algo que acabaría provocándole problemas coronarios a partir de 2004.

En cuanto al caso español, diversas sociedades científicas vienen realizando en los últimos años trabajos de campo acerca de la salud de nuestros políticos, con resultados no muy positivos y que parecen ir en contra de la imagen que intentan proyectar. Por ejemplo, la Fundación Española del Corazón ha puesto en evidencia que el 50\% de los congresistas y senadores padece sobrepeso u obesidad, el $29 \%$ es hipertenso, el $27 \%$ tiene unas cifras elevadas de colesterol y, en conjunto, más de tres cuartas partes presentan algún factor de riesgo que aumenta significativamente sus posibilidades de desarrollar algún problema coronario (Lucio, 2011). De hecho, no son pocos los políticos españoles que han sufrido anginas o infartos en el desempeño de sus funciones, como el líder de Izquierda Unida (IU) Julio Anguita, el presidente extremeño Rodríguez Ibarra, el dirigente de Esquerra Republicana de Cataluña (ERC) Carod Rovira o los diputados Joaquín Leguina y Juan José 
Laborda, entre otros. Y esta realidad coincide bastante con análisis realizados en Estados Unidos acerca del riesgo cardiovascular de los candidatos presidenciales (DeMaria, 2003).

Pero en esta comprobación empírica de los hábitos saludables de los políticos y la discordancia entre lo que dicen y lo que verdaderamente hacen, un relato periodístico conmocionó a Italia en octubre de 2006, al revelarse que uno de cada tres diputados consumía algún tipo de droga (principalmente hachís y cocaína), justo pocas semanas después de que esos mismos diputados hubieran aprobado el endurecimiento de las penas por consumo y tenencia de estas sustancias ( $E l$ Mundo, 11 de octubre de 2006). El impacto que ocasionó esta revelación llevó al presidente de la Cámara a estudiar incluso el someter a los diputados a controles antidoping, similares a los que se practican a los deportistas, para terminar de cerrar la polémica (La Razón, 17 de febrero de 2007).

En todos estos casos se produce una ruptura del principio de ejemplaridad, en tanto que, como se acaba de apuntar en el caso italiano, la opinión pública descubre que lo que pregonan los políticos no se corresponde con lo que llevan a la práctica finalmente. Esto se aplica también, por ejemplo, cuando se debate acerca del lugar en el que son atendidos los políticos cuando enferman, entroncando con la eterna polémica que hay en muchos países acerca de la sanidad pública y la sanidad privada. Si son tratados en centros privados, pueden estar sometidos a la crítica de que no confían en la sanidad pública o de comportamientos elitistas, y más aún en los casos en los que hay discordancia entre el discurso que se ha mantenido en el pasado y lo que se acaba haciendo cuando llega el caso, uno de los problemas comunicativos que más pueden afectar a las instituciones (Canel, 2007). Esto le ocurrió a la presidenta argentina Cristina Fernández de Kirchner que, a pesar de contar con una habitación presidencial en un hospital público y de que miembros de su gobierno hubieran criticado en ocasiones a otros políticos por el hecho de decantarse por la sanidad privada, al final acabó yendo a uno de los centros más lujosos y exclusivos del país cuando se tuvo que operar por su problema de tiroides $(A B C, 31$ de diciembre de 2011).

Pero hay también debates que van más allá. Por ejemplo, el hecho de que Hugo Chávez se trasladara a Cuba para tratarse su cáncer, fue utilizado por diversos medios y por candidatos opositores para criticar que el presidente no confiaba en los profesionales de su país, algo que sufrió también el paraguayo Fernando Lugo cuando decidió operarse también de su cáncer en Brasil (BBC Mundo, 10 de agosto de 2010).

\section{La actividad política, ¿̨origen de posibles enfermedades?}

Hasta el momento se ha hablado de la buena salud de los políticos y de cómo este factor puede ser utilizado en la estrategia comunicativa de un gobierno o un partido para mejorar la imagen del líder. Pero convendría detenerse también en cómo la enfermedad puede tener asimismo importantes repercusiones en este ámbito. 
Porque de lo dicho hasta ahora podría desprenderse que para dedicarse hoy día a la política es imprescindible tener buenas capacidades físicas. Y, aunque es un factor a tener en cuenta, no puede caerse en una visión estereotipada en torno a este asunto. En el libro de Owen citado al inicio de este trabajo se narra la experiencia de grandes políticos que arrastraron durante su vida importantes problemas de salud, lo que no impidió que pudieran desempeñar su labor, incluso con altas dosis de popularidad. En esta misma línea, los medios de comunicación están reportando también en los últimos años numerosos casos de líderes que se han tenido que enfrentar a una enfermedad tan dura como el cáncer sin dejar sus responsabilidades públicas, como Ehud Olmert (Israel), Rudolph Guiliani (Estados Unidos), Patrick Manning (Trinidad y Tobago), Hugo Chávez (Venezuela), Lula da Silva y Dilma Rousseff (Brasil), Fernando Lugo (Paraguay), Juan Manuel Santos (Colombia) o Loyola y Ana de Palacio, Esperanza Aguirre, María San Gil, José Montilla, Iñaki Azkuna, José Antonio Labordeta y Uxue Barkos (España), entre otros.

El duro ritmo que impone la política podría llevar también a la conclusión de que lo normal es que la salud de quienes la ejercen acabe resintiéndose. Y, desde luego, en muchos casos es así. Los políticos se ven obligados a llevar un estilo de vida plagado de estrés, constantes viajes, comidas de trabajo a veces poco equilibradas, entrevistas, reuniones... Un estilo que, a veces, está reñido con lo que se consideran hábitos saludables de vida y que, de hecho, suele pasarles factura incluso en su apariencia física. Es frecuente, por ejemplo, que aparezcan noticias en los medios en las que se compara mediante fotografías cómo el cargo de presidente o de primer ministro ha ido envejeciendo a muchos políticos con el transcurso de los años (con signos como canas, arrugas, ojeras...).

Esta actividad comporta, por tanto, el estar sometidos a mucha presión, lo que pone el énfasis no sólo en la salud física sino también en la salud mental. El tener que enfrentarse a momentos o decisiones difíciles, crisis, críticas desde las filas rivales, ataques de los medios de comunicación, la sensación de soledad o aislamiento, o la ridiculización y descrédito por parte de la opinión pública, son factores que ponen muchas veces a prueba la resistencia psíquica de los políticos (Park, 1986; Flórez, 1996; Torbeña, 2008; Owen, 2010). Y, de hecho, diversos estudios han puesto de manifiesto que la frecuencia de enfermedades mentales, como depresiones, trastornos bipolares o síndrome de hybris, entre otras, podría afectar a entre el 20 y el 40\% de los políticos, porcentajes sensiblemente más altos a los registrados entre la población general (Lucio, 2011).

Y si estos problemas se ponen en evidencia durante el desarrollo habitual de la actividad política, se acrecientan aún más en las campañas electorales. Antonio Cano, presidente de la Sociedad Española para el estudio de la Ansiedad y el Estrés, dice que "los políticos en campaña incrementan considerablemente su estrés. No puede ser de otra manera, por mucho que ellos o sus oficinas de prensa lo nieguen". De la misma opinión es Julio Zarco, expresidente de la Sociedad Española de Médicos de Atención Primaria (SEMERGEN), para quien "una campaña es un punto en el tiempo muy acotado, afortunadamente, pero, al fin y al cabo, es un mes de tensión, cambio de hábitos y desarraigo familiar. Hay quien lo supera sin problema, pero otros pueden sufrir trastornos generalizados o psicosomáticos". Por último, María Jesús Salvador, de la So- 
ciedad Española de Cardiología, recuerda también que una campaña, y el periodo previo de precampaña (que puede durar varios meses), son “enemigos cardiovasculares" (Jiménez y Pérez, 2008).

Y de todo esto son plenamente conscientes tanto los propios políticos como quienes les asesoran. El consultor español José Luis Sanchís reconoce que "el trabajo del candidato exige una continuada comparecencia ante la opinión pública, viajes en cadena y, en suma, un esfuerzo físico agotador. Por tanto, es imprescindible prepararse, tanto física como moral e intelectualmente (...). Corazón y garganta son los dos órganos con mayor peligro en una campaña” (1996: 153).

En definitiva, el ejercicio de la política desgasta y, en muchas ocasiones, está detrás de importantes contratiempos para la salud. El neurólogo y periodista Nelson Castro ha hecho un detallado análisis de cómo el ejercicio de la presidencia en Argentina ha conllevado un alto número de muertes y enfermedades. De hecho, cuatro presidentes fallecieron en el cargo y otros seis, entre ellos Menem, De la Rúa o Kirchner, sufrieron fuertes complicaciones durante sus mandatos (Castro, 2006).

En Estados Unidos se ha desarrollado también una prolífica labor investigadora acerca de los problemas de salud que han padecido los inquilinos de la Casa Blanca y las repercusiones que esto ha tenido en sus decisiones (Bumgarner, 1994; Gilbert, 1998; McDermott, 2008; Blumenthal y Morone, 2009), aunque hay trabajos que han venido a afirmar que este cargo no siempre está asociado a una menor esperanza de vida. Jay Olshansky, de la Universidad de Illinois, ha descubierto por ejemplo que los presidentes estadounidenses han sido casi siempre más longevos que sus contemporáneos y que, por tanto, podría decirse que la presidencia posee un efecto "alargador" de la vida entre quienes la han ejercido (Olshansky, 2011).

\section{El dilema comunicativo de ocultar, mentir o reconocer las enfermedades}

Pero en relación a las enfermedades que pueden sufrir los políticos, quizá el momento más delicado en el campo de la comunicación es aquél en el que se tiene que tomar la decisión de informar o no a la opinión pública de esas dolencias.

Y es que, como recuerda Muñoz Alonso (1989), cuando un político se encuentra de frente con la evidencia de padecer una enfermedad, y más si es grave, surge una primera disyuntiva: ¿̨hasta qué punto esta información debe darse a conocer a los ciudadanos o mantenerse en secreto? Cuando se alude con tanta frecuencia por parte de personajes públicos a la necesidad de que se respete su "vida privada", se podría pensar que una enfermedad grave entra dentro de este ámbito. A este respecto, el consultor de comunicación Antoni Gutiérrez-Rubí cree que "todo lo que afecta a la salud de las personas es privado, pero en el caso de los políticos es público y los ciudadanos tienen derecho a saber cuál es el estado de salud de sus gobernantes" (ARA, 14 de marzo de 2011). En definitiva, se trata de una cuestión de "sinceridad" con el electorado, como reconoce Owen, para quien "debe constituir una obligación reconocida que todo dirigente político que decida presentarse al cargo sea sincero en lo que se refiere a su salud” (2010: 440), una opinión compartida por otros autores como Annas 
(1995), Streiffer, Rubel y Fagan (2006) o Brody (2011) que consideran, sin embargo, que este principio debe aplicarse con algunas salvedades y pensando sobre todo en aquellas dolencias que puedan afectar directamente a su trabajo.

Las constituciones de muchos países contemplan la posibilidad de declarar la incapacidad para el mando de los presidentes en aquellos casos en los que no puedan ejercer su función, por ejemplo por enfermedad grave, principalmente vinculada a la pérdida de facultades mentales o a estados irreversibles en los que no se prevé recuperación (Reviriego, 2003). En el recuerdo queda el caso del presidente ecuatoriano Abdalá Bucaram, que estuvo en el cargo entre 1996 y 1997 , año en el que fue destituido por incapacidad mental por el Congreso del país (El País, 28 de abril de 2009) o el del primer ministro israelí Ariel Sharon, que fue relevado tras sufrir su segundo infarto cerebral en 2006 (La Vanguardia, 7 de febrero de 2006).

Pero exceptuando estos casos graves, reglamentados incluso por ley, lo que se plantea aquí es si el hecho de dar a conocer una posible enfermedad tiene repercusiones no ya tanto en su gestión como sobre la imagen y valoración popular de los políticos afectados, lo que conllevaría la necesidad de acciones específicas de comunicación. Y estas acciones pueden desarrollarse en cualquiera de estos dos escenarios: ocultar o mentir sobre la enfermedad o, en el lado contrario, reconocerla públicamente.

\subsection{Ocultación de la enfermedad y el uso de la mentira}

Muchos son los políticos que a lo largo de la historia han ocultado o mentido a sus ciudadanos sobre una posible enfermedad. Y esta ocultación puede ir desde el silencio hasta la negación, siguiendo la clásica graduación de la mentira propuesta por Durandin (1983).

\subsubsection{Ocultar: la práctica de la omisión}

Una primera forma de actuar es simplemente callar, no decir nada acerca de la supuesta enfermedad, bien porque el emisor decide ocultarla o bien porque obliga a un tercero a mantenerla en silencio (como en el caso de la censura). De hecho, la ocultación de las enfermedades de los líderes ha sido una práctica habitual en la historia de la humanidad, principalmente en los países de corte autoritario, donde la salud del máximo dirigente es tratada como un secreto de Estado.

Y así ha quedado en evidencia en múltiples casos, desde los problemas de salud nunca reconocidos de los presidentes de la Unión Soviética (de los que la mayoría de las veces no se tenía conocimiento hasta el mismo momento de su muerte) a los que puedan haber sufrido los líderes chinos, de Corea del Norte, de países africanos o del mundo árabe y también en el régimen cubano (Robins y Post, 1992; Pizarroso, 1993). Y en nuestro país, durante el franquismo, hubo también diversos episodios en los que el régimen ocultó las complicaciones de salud del jefe del Estado en los últimos años de su mandato (Prego, 1997). 
En estos regímenes, reconocer que el líder sufre alguna dolencia puede ser interpretado como una señal de debilidad de la que podrían aprovecharse los "enemigos" del país, tanto internos como externos. Por eso el secreto es visto como imprescindible: no se difunden datos, se exige máxima confidencialidad al personal sanitario implicado (a veces incluso bajo amenazas), se ocultan las verdaderas dolencias en los informes médicos para que no quede constancia por escrito, se prohíbe la publicación de noticias o fotografías que puedan inducir a dar una imagen de deterioro...

Pero ocultar enfermedades no es algo exclusivo de los países autoritarios. En las modernas democracias hemos asistido también a casos de políticos que han guardado silencio sobre posibles problemas de salud. Diversos trabajos han analizado el encubrimiento de enfermedades en el caso de los presidentes de Estados Unidos (MacMahon y Curry, 1987; Crispell y Gómez, 1988; Ferrell, 1992). Quizá uno de los más significativos fue el de Franklin D. Roosevelt, postrado en silla de ruedas por un problema de polio en su juventud, hecho que ocultó sistemáticamente a los periodistas y, en definitiva, al pueblo americano porque no quería que le vieran como a un inválido. Como recuerda Owen, "siendo presidente se intentó dar la impresión, en las ocasiones importantes, de que podía ponerse de pie, e incluso ideó un método para dar unos pocos pasos, de modo que pareciera que podía andar con sólo un ligero apoyo" (2010: 84). De hecho, prosigue este autor, "de las 35.000 fotografías que se conservan en la Roosevelt Presidential Library, sólo dos lo muestran en silla de ruedas” (2010: 84).

El propio Owen cita casos similares en otros países. En Reino Unido, Churchill ocultó también el haber sufrido un ataque cardíaco a finales de 1941, por miedo a que esta noticia supusiera un mazazo emocional para el país en medio de la Segunda Guerra Mundial. En Alemania, las depresiones de Willy Brandt, que le obligaban cada cierto tiempo a permanecer en cama varios días, eran escondidas por su equipo bajo la apariencia de simples gripes. Y en Francia, Pompidou silenció también su leucemia, de la que la opinión pública no fue conocedora hasta bastantes años después de la muerte del presidente. También en el país galo despertó gran polémica la ocultación del cáncer que padecía Mitterrand, que no fue admitido hasta 11 años después de su diagnóstico.

En las democracias actuales, sin embargo, el silencio tiene muchos riesgos y es que es muy difícil que los periodistas no acaben enterándose y difundiendo este tipo de noticias. Hace unos cuantos años aún podía darse el caso de que un político pudiera pactar con los principales medios de comunicación el que mantuvieran en secreto una posible enfermedad. Pero en una época como la actual en la que el sensacionalismo está en auge, en la que los rumores circulan libre y anónimamente por la Red y acaban llegando incluso a los medios tradicionales y en la que cada vez tiene más fuerza también el "periodismo ciudadano" auspiciado por el éxito de las redes sociales, cualquier político entrando por la puerta de un hospital puede ser visto e incluso fotografiado por ciudadanos anónimos que den a conocer el hecho. "El problema de no decirlo -apunta el catedrático Francesc Xavier Ruiz- es que fácilmente se puede filtrar a través de otras fuentes y eso genera especulaciones y desconfianza respecto al político en cuestión" (ARA, 14 de marzo de 2011). En resumen, la opinión pública puede sentirse engañada y eso repercute negativamente en la imagen del político. 
Por otro lado, siempre puede resultar sospechoso que un líder se ausente durante varios días (y más aún si son semanas), algo que hace desatar de forma inmediata los rumores. Este fue el caso del líder chino Xi Jinping, cuando en septiembre de 2012 estuvo más de dos semanas sin dar señales de vida, lo que suscitó numerosas especulaciones a nivel internacional sobre una enfermedad grave e, incluso, sobre su posible fallecimiento, generando también incertidumbre entre la propia población china a pesar de los intentos de censura del régimen (El País, 15 de septiembre de 2012). Otro caso similar fue el de la política india Sonia Gandhi, que desapareció de la vida pública durante varios meses en 2011 y eso hizo disparar también los rumores acerca de su estado de salud, rumores que se acrecentaron cuando se conoció que había viajado a Estados Unidos para tratarse de una enfermedad de la que, sin embargo, no se dio ninguna información (Reuters, 2 de octubre de 2011). De hecho, muchas dolencias de líderes extranjeros de países del tercer mundo se han acabado conociendo precisamente a raíz de viajes a Estados Unidos u otros países desarrollados para ser tratados, una información que, en el caso de las dictaduras, es silenciada en sus naciones de origen pero que sí termina siendo difundida a nivel internacional.

\subsubsection{Negar: mentira por comisión}

Pero la estrategia de guardar silencio se viene abajo cuando empiezan a saltar rumores o a aparecer noticias sobre la enfermedad que se está intentando ocultar, algo muy frecuente puesto que los posibles achaques de los políticos es uno de los temas más sujetos a rumorologías y especulaciones periodísticas (Lehman-Wilzig, 2003). En estos casos, y si se quiere seguir adelante con la táctica de no reconocimiento de la dolencia, la única salida es la negación, es decir, desmentir públicamente esas informaciones.

Un caso paradigmático a este respecto fue el del presidente de Venezuela, Hugo Chávez. Cuando en 2011 se desataron los rumores tras permanecer en Cuba varias semanas por razones médicas no explicadas, periódicos extranjeros empezaron a hablar de que podría padecer cáncer. Esta información fue desmentida en varias ocasiones por el gobierno, diciendo que se trataba de maniobras de propaganda de Estados Unidos para atacar a Venezuela, a pesar de que tiempo después tuvieron que reconocer que efectivamente sí padecía dicha enfermedad.

Pero ha habido también otros ejemplos. En 1893, el presidente estadounidense Grover Cleveland ocultó a la ciudadanía que había sido operado de cáncer, puesto que temía que un presidente enfermo podría deprimir aún más a Wall Street, que pasaba entonces por una fuerte crisis, y sembrar el pánico. Sin embargo, hubo un redactor del Philadelphia Press que publicó la noticia en base a testimonios de uno de los médicos que habían atendido al presidente. Cleveland lo negó e incluso inició una campaña de descrédito contra el periodista que prácticamente acabó con su carrera (Algeo, 2011).

Casi cien años después, en la campaña estadounidense de 1960, empezaron también a saltar rumores sobre los problemas de salud de Kennedy, aspirante demócrata a la presidencia. Para intentar acallarlos, su equipo difundió a la prensa un ex- 
tenso historial médico en el que se probaba que el candidato gozaba de un excelente estado de salud, algo que en realidad era falso, puesto que se habían omitido sus principales dolencias (Dallek, 2004).

Hay ocasiones también en las que, ante rumores, se decide optar no tanto por los desmentidos oficiales como por el hecho de dar muestras "gráficas" o pruebas aparentemente incontrovertibles de que esas informaciones son falsas. Corría el año 1966 cuando en China se desataron una serie de guerras internas en el Partido Comunista por la supuesta debilidad de Mao debido a su edad (entonces tenía 73 años). En este contexto, el aparato de propaganda del gobierno difundió unas imágenes de Mao nadando en el río Yangtsé, afirmando incluso que el líder había sido capaz de cruzar sin problemas los más de 13 kilómetros que separaban las dos orillas en un tiempo récord (Ferrer, 1995). Aquel gesto fue un claro mensaje a quienes podían estar pensando en seguir alentando los rumores y, de hecho, fue interpretado como un golpe de autoridad por parte de Mao tanto a nivel interno como de proyección pública hacia el exterior.

Pero la práctica de negar o desmentir la enfermedad tiene un riesgo muy importante en términos de comunicación y de confianza por parte de los medios y los ciudadanos. Y es que si, con el tiempo, se acaba demostrando que lo que se venía negando al final era verdad, se produce la lógica pérdida de credibilidad para el político o la institución, algo que será después muy difícil recuperar.

\subsection{El reconocimiento público de la enfermedad}

A pesar de que son muchos los políticos que han ocultado o mentido acerca de sus enfermedades, la realidad es que la actual sociedad de la información, en la que tarde o temprano todo acaba saliendo a la luz y en la que los líderes están expuestos a una mayor presencia mediática, está llevando a que cada vez sea más frecuente que los políticos den a conocer sus dolencias a la opinión pública en un acto de transparencia que tiene implicaciones tanto para su gestión como para su proyección pública.

La política española María San Gil, líder durante varios años del Partido Popular del País Vasco, recoge en sus memorias que en el momento en el que le diagnosticaron cáncer tuvo claro qué debía hacer. "Con la verdad siempre se acierta, es lo mejor. No tenía ningún sentido inventarnos una historia para ocultar la verdad” (2011:279).

Y esta práctica es cada vez más común. También en España, éste ha sido el caso de otros políticos antes mencionados, que han reconocido públicamente su enfermedad desde el primer momento. Incluso se ha alabado por parte de los medios de comunicación la transparencia que ha mostrado la Casa Real en lo relativo a las sucesivas intervenciones que desde 2010 se le han practicado al Rey. Y lo mismo está ocurriendo fuera de nuestras fronteras.

¿Cómo afecta a los políticos el hecho de reconocer abiertamente que están enfermos? En este campo, hay una doble perspectiva. Por un lado, esta información puede ser vista como un síntoma de debilidad o pérdida de capacidades para 
desempeñar el puesto, lo que contribuye a generar incertidumbre. La confirmación de que el presidente Reagan padecía cáncer supuso, por ejemplo, que la bolsa de Nueva York cayera ese día 3,4 puntos (El País, 16 de julio de 1985). Y el infarto sufrido por Julio Anguita en plena campaña española de 1993, que le obligó a estar ausente en la recta final, fue uno de los factores que provocaron que los resultados de Izquierda Unida se quedaran bastante por debajo de lo que habían pronosticado todos los sondeos (Pastor, 1993).

Esta incertidumbre sobre la salud de los políticos es algo que pueden aprovechar los partidos rivales en el marco de las campañas negativas y que puede ser exprimido también por los medios de comunicación, que, consciente o inconscientemente, acaban trasladando este debate a la opinión pública (Bloom, 1976).

Muchos son los líderes que se han visto en esta circunstancia, en la que se entremezclan cuestiones de ética política y periodística y también de respeto a la dignidad de quienes sufren la enfermedad, preceptos que no siempre se tienen en cuenta (Lehman-Wilzig, 2003). El presidente Eisenhower vio cómo la oposición sembró dudas entre los votantes en la campaña de 1956 acerca de su capacidad para repetir mandato tras haber sufrido un ataque al corazón (Jamieson, 1984). Cuatro años después, en 1960, Nixon fue acusado del intento de robo de historiales médicos de Kennedy con el objetivo de desenmascararle y de echar por tierra la supuesta buena salud del líder demócrata durante la campaña (Dallek, 2004).

En el Reino Unido, las taquicardias detectadas a Toni Blair en octubre de 2003, por las que tuvo que ser hospitalizado, acarrearon numerosas especulaciones políticas y periodísticas. “¿Cuánto tiempo lo va a soportar?”, se preguntaba en portada el diario The Times que, como otros medios, empezaron a cuestionarse si el primer ministro podría aguantar mucho más en el puesto (El País, 21 de octubre de 2003). También en el Reino Unido, Gordon Brown tuvo que salir al paso en septiembre de 2009 de numerosas informaciones acerca de que podía estar pensando abandonar el cargo por problemas de salud y por su supuesta dependencia a los fármacos para afrontar la dura tarea de ser primer ministro (El País, 29 de septiembre de 2009).

El jefe de Estado francés Jacques Chirac vio también cómo sus accidentes cerebrovasculares durante 2005 sirvieron para que se generara un amplio debate político y mediático acerca de la idoneidad para seguir en el cargo, un debate acrecentado además por la edad del presidente, que sobrepasaba los 70 años (La Razón, 4 de septiembre de 2005). Y en Rusia, el frágil estado del presidente Yeltsin por sus problemas de alcoholismo y sus numerosos achaques se convirtió en la principal noticia de los medios durante la campaña electoral de 1996 y también en uno de los argumentos más citados por los partidos de la oposición para menoscabar su imagen e intentar frenar su reelección (Treisman, 1996).

Se aprecia, por tanto, que el hecho de estar enfermo puede suponer un problema inicial en la carrera política y más aún cuando se trata de enfermedades mentales, sobre las que siguen existiendo muchos estigmas sociales. Pero, por otro lado, 
se está comprobando también desde hace un tiempo que hay líderes que, gracias sobre todo a la forma de asumir y comportarse públicamente ante la enfermedad, son capaces de aumentar su popularidad y la estima por parte de los ciudadanos.

Este aspecto está muy vinculado a la personalización de la política que se apuntó anteriormente, en la que las características personales de los líderes tienen una gran influencia hoy día sobre las percepciones de los electores. Y si la imagen que proyectan ante la enfermedad es la de luchadores, optimistas, que no se dejan vencer por el miedo y que dan ejemplo a otras personas anónimas que pueden estar pasando por su misma situación, sin duda la valoración que la gente tiene de ellos puede salir reforzada. En palabras del asesor de comunicación Yuri Morejón, "se da una sensación de humanidad enorme que, además, genera empatía, ya que todo el mundo, con independencia de la ideología que pueda tener, ha sufrido en primera persona o a su alrededor, ya sea la familia o amigos, una situación similar" (El Diario Vasco, 3 de marzo de 2011).

Entra aquí de lleno lo que hoy día se conoce como "storytelling", el hecho de fabricar, consciente o inconscientemente, un relato de hombres y mujeres valientes ante la enfermedad, dispuestos a seguir sacrificándose por el bien colectivo a pesar de sus dolencias y que proyectan una aureola emocional de fortaleza y superación que es bien vista por la opinión pública (Núñez, 2007). En muchos casos, se recurre incluso a una imagen mítica, convirtiendo en héroes o mártires a estos políticos. A este respecto, resulta curioso cómo Hugo Chávez, a pesar de haber ocultado su cáncer en los primeros momentos, consiguió un efecto de estas características después de reconocerla abiertamente en junio de 2011. De hecho, su popularidad aumentó en más de diez puntos en apenas tres meses, de julio a septiembre, alcanzando sus máximas cotas de valoración desde hacía más de seis años (El Mundo, 5 de octubre de 2011). Como afirma Carlos Blanco, profesor de Asuntos Latinoamericanos de la Universidad de Boston, “Chávez manejó con destreza su enfermedad: pasó de ser el 'presidente enfermo' a ser el 'presidente mártir', lo que le permitió conservar un apoyo importante" (Associated Press, 13 de junio de 2012).

En este punto, podría considerarse poco ético que un político intente aprovechar su enfermedad con fines electoralistas o partidistas. Precisamente ésta fue una de las críticas que se lanzaron contra Cristina Fernández de Kirchner, presidenta de Argentina, en diciembre de 2011, cuando anunció públicamente que se iba a someter a una operación para tratar un cáncer de tiroides que finalmente, y tras varios días de conmoción en el país, fue descartado. Varios partidos de la oposición y medios críticos con la presidenta publicaron que todo había sido una estrategia del gobierno para desviar la atención de la ciudadanía acerca de los problemas de la nación y tejer así una cortina de humo.

Resulta muy difícil comprobar si este tipo de estratagemas son reales o meras teorías conspirativas. En cualquier caso, podría pensarse que muy probablemente la gran mayoría de los que pasan por situaciones así no tienen en mente buscar réditos, sino simplemente afrontar de la mejor manera posible su dolencia. Por eso los consultores políticos se muestran 
prudentes. "Quiero creer que ninguno lo utiliza en clave electoral y los ciudadanos detectan enseguida si hay sobreactuación”, afirma Gutiérrez-Rubí (ARA, 14 de marzo de 2011). Y de la misma opinión es el experto en campañas Gustavo Santiago, para quien "llamar la atención sobre sus problemas de salud buscando empatía electoral puede resultar contraproducente" (Smink, 2010).

En el lado contrario, se ha puesto en entredicho también si es ético o no criticar a un oponente por sus problemas de salud (Bloom, 1976), así como el posible beneficio electoral que puede obtenerse por actuar de esta forma. Es verdad que existen casos en los que con estas críticas se ha logrado el objetivo de trasladar preocupación a la opinión pública y, así, erosionar la imagen del líder enfermo. Pero en este campo entra a veces también en juego uno de los efectos más estudiados en las campañas electorales, conocido como under dog, esto es, la tendencia que puede sentir el electorado a mostrar compasión y acabar apoyando a aquel candidato que parte con desventaja y al que todo parece ponérsele cuesta arriba, como puede ser en estos casos de enfermedad grave. En definitiva, podría darse un efecto boomerang, es decir, que los ataques acabaran volviéndose en contra de quien los lanza (Canel, 2006).

\section{Conclusiones: la salud y la enfermedad como valores estratégicos en la comunicación política}

En una época de personalización y humanización de la política, en la que las cualidades de los líderes cobran cada vez más importancia, su estado de salud y sus posibles enfermedades han pasado a ser una variable comunicativa más que debe ser tenida en cuenta por los asesores por las implicaciones que puede tener sobre la imagen pública, valoración y notoriedad tanto de los propios líderes como de las instituciones o partidos que representan.

Un buen estado de salud, dinamismo, capacidad de resistencia y fortaleza, tanto física como mental, son aspectos bien vistos por la opinión pública y los políticos se afanan en hacer demostraciones empíricas de estas cualidades ante los medios de comunicación, que se muestran muy receptivos a difundir este tipo de noticias, lo que sin duda aumenta su notoriedad y repercusión. Estamos por tanto aquí ante una actitud proactiva por parte de los aparatos de comunicación de las instituciones, en el sentido de que intentan explotar intencionalmente estas variables en beneficio de la imagen de su líder. En el lado contrario, el sufrir una enfermedad puede ser interpretado inicialmente como un lastre para la carrera del político y un problema en términos de repercusión en la opinión pública, por lo que los gabinetes y asesores deberán planificar también desde el punto de vista de la comunicación cómo afrontar esta situación sobrevenida.

Y en este punto cobra especial importancia no tanto el hecho de que el líder esté sano o enfermo sino precisamente el cómo se enfrentan las instituciones a estos casos. Porque una buena política de comunicación puede ayudar al líder y a la entidad a afrontar los problemas que inicialmente podrían plantearse, llegando a reforzar incluso su imagen y prestigio público. Y, en el lado inverso, una mala praxis puede generar confusión, rumores, incertidumbre entre la población e incluso inestabilidad política, que son siempre caldo de cultivo para bajadas de valoración y popularidad. 
No se trata aquí de explotar emocionalmente una posible enfermedad ni de intentar aprovechar esta circunstancia con intenciones electoralistas. Este tipo de actuaciones, además de resultar poco éticas, son castigadas finalmente por la opinión pública. De lo que se trata es de afrontar comunicativamente una circunstancia que, se quiera o no, tiene implicaciones en el campo político y, por tanto, en el de la comunicación política.

Tras conocer la enfermedad, y más cuando ésta es grave, el líder deberá valorar si desea seguir o no en el cargo, pensando sobre todo en las limitaciones que puede suponer para su desempeño. Y si decide continuar, deberá sopesar los riesgos de reconocer públicamente o no dicha dolencia. Porque esa decisión, y lo que ella comporta, por muy frío o impersonal que pueda parecer, puede ser fundamental en términos tanto personales (para el propio político) como institucionales. Y en plena sociedad de la información, donde resulta cada vez más difícil mantener cuestiones en secreto, la tendencia que va consolidándose es la de actuar con transparencia. La estrategia basada en ocultar información, mentir, negar los rumores o ir a contracorriente desmintiendo las informaciones que los medios puedan ir publicando (casi siempre procedentes de fuentes interesadas), puede ocasionar mucho daño en términos políticos y precisamente por ello es cada vez menos usada. En definitiva, podrían trasladarse aquí los principios que se aplican en el ámbito de la comunicación de crisis en las organizaciones, en el que la verdad, la transparencia, el llevar la iniciativa y el actuar de forma planificada resultan fundamentales para gestionar eficazmente dichas crisis.

\section{Bibliografía}

Algeo, Matthew (2011): The president is a sick man. Chicago: Chicago Review Press.

Annas, George J. (1995): "The health of the president and presidential candidates: the public's right to know", The New England Journal of Medicine, vol. 333, $\mathrm{n}^{\circ}$ 14, pp. 945-949.

Arroyo, Luis (2012): El poder político en escena. Barcelona: RBA.

Berrocal, Salomé (2003): “La personalización en la política”, en Berrocal, Salomé (coord.): Comunicación política en televisión y nuevos medios. Barcelona: Ariel, pp. 55-79.

Berrocal, Salomé (2004): “Una aproximación a la nueva retórica del líder televisivo: acciones, cualidades y discurso”, Doxa, no 2, pp. 53-67.

Bloom, M. (1976): “Should the health of presidential candidates be a campaign issue?”, Medical World News, vol. 17, n 3, pp. 34-99.

Blumenthal, D. y Morone, James A. (2009): The heart of power: health and politics in the Oval Office. Berkeley: University of California Press.

Brody, Howard (2011): “How much about a president's health do the public have a right to know?", The New Republic, 22 de julio. 
Bumgarner, John R. (1994): The health of the presidents. Jefferson: McFarland \& Co.

Canel, María José (2006): Comunicación política: una guía para su estudio y práctica. Madrid: Tecnos.

Canel, María José (2007): Comunicación de las instituciones públicas. Madrid: Tecnos.

Castro, Nelson (2005): Enfermos de poder: la salud de los presidentes y sus consecuencias. Buenos Aires: Ed. Javier Vergara.

Chrisafis, Angelique (2007): “Cómo se ponen en forma los líderes del mundo”, The Guardian/El Mundo, 22 de julio.

Crispell, Kenneth y Gómez, Carlos F. (1988): Hidden illness in the White House. Durham: Duke University Press.

Curry, Tom (2008): “Candidates' health can decide an election”, en msnbc.com, 23 de mayo. Extraído el 5 de enero de 2012 de: http://www.msnbc.msn.com/id/23749867/ns/politics-decision_08/t/candidates-health-can-decide-election/

Dallek, Robert (2004): J.F. Kennedy: una vida inacabada. Barcelona: Península.

DeMaria, Anthony N. (2003): "Presidential candidates and cardiovascular risk", Journal of the American College of Cardiology, vol. 41, pp. 1.631-1.632.

Denton, Robert E. (ed.) (2002): The 2000 presidential campaign: a communication perspective. Westport: Praeger.

Denton, Robert E. (ed.) (2005): The 2004 presidential campaign: a communication perspective. Lanham: Rowman \& Littlefield.

Durandin, Guy (1983): La mentira en la propaganda política y en la publicidad. Barcelona: Paidós.

Ferrell, Robert H. (1992): Ill-advised: presidential health and public trust. Columbia: University of Missouri Press.

Ferrer Rodríguez, Eulalio (1995): De la lucha de clases a la lucha de frases: de la propaganda a la publicidad. Madrid: El País.

Flórez Tascón, Francisco José (1996): El poder enfermo: la salud de diez líderes políticos del siglo XX. Madrid: Temas de Hoy.

Gilbert, Robert E. (1998): The mortal presidency: illness and anguish in the White House. Nueva York: Fordham University Press.

Hart, Roderick P. (1994): Seducing America: how television charms the modern voter. Nueva York: Oxford University Press. Jamieson, Kathleen Hall (1984): Packaging the presidency. Nueva York: Oxford University Press.

Jiménez, A. y Pérez P. (2008): “Políticos: se dejan la salud en la campaña electoral”, Salud (La Razón), 9 de marzo.

Johnson, Dennis W. (2009): Campaigning for president 2008: strategy and tactics, new voices and new techniques. Nueva York: Routledge.

Lehman-Wilzig, Sam N. (2003): "Political ill-health coverage: professional-ethical questions regarding news reporting of leaders' ailments”, Journal of Health Communication, vol. 8, n 1, pp. 59-77. 
Lucio, Cristina G. (2011): “Chequeo a los políticos”, Eureka (El Mundo), 13 de marzo.

Mark, David (2009): Going dirty: the art of negative campaigning. Lanham: Rowman \& Littlefield.

MacMahon, Edward B. y Curry, Leonard (1987): Medical cover-ups in the White House. Washington D.C.: Farragut Pub. Co. McDermott, Rose (2008): Presidential leadership, illness, and decision making. Nueva York: Cambridge University Press. Muñoz Alonso, Alejandro (1989): Política y nueva comunicación. Madrid: FUNDESCO.

Núñez, Antonio (2007): ¡Será mejor que lo cuentes!: los relatos como herramientas de comunicación. Barcelona: Empresa Activa.

Olshansky, Jay (2011): "Aging of US Presidents", The Journal of the American Medical Association (JAMA), vol. 306, nº. 21, pp. 2.328-2.329.

Owen, David (2010): En el poder y en la enfermedad. Madrid: Siruela.

Park, Bert. E. (1986): The impact of illness on world leaders. Philadelphia: University of Pennsylvania Press.

Pastor, Carles (1993): “El infarto rompió la estrategia”, El País, 6 de junio.

Pizarroso Quintero, Alejandro (1993): Historia de la propaganda. Madrid: Eudema.

Prego, Victoria (1997): Así se hizo la Transición. Barcelona: Plaza \& Janés.

Rees, Laurence (1992): Selling politics. Londres: BBC Books.

Reviriego Picón, Fernando (2003): “La incapacidad del Presidente del Gobierno y de los presidentes autonómicos”, Saberes. Revista de estudios jurídicos, económicos y sociales, vol. 1, pp. 1-26.

Robins, Robert S. y Post, Jerrold (1992): When illness strikes the leader. New Haven: Yale University Press.

Rodríguez Andrés, Roberto (2013). "La fuerza electoral de las personas mayores: comportamiento de voto y estrategias para persuadir a un colectivo cada vez más decisivo en campañas”, en Sanders, K., Capdevilla, A. y Canel, M.J. (eds.). Estudios de Comunicación Política: Libro del año 2012. Madrid: Tecnos.

Rodríguez Andrés, Roberto y Ruiz de Galarreta, Laura (1996): “Elecciones USA: cara o cruz”, Diario de Noticias, 3 de noviembre.

Sanchís, José Luis (1996): Cómo se gana el poder. Madrid: Espasa.

San Gil, María (2011): En la mitad de mi vida. Barcelona: Planeta.

Schwartzenberg, Roger-Gérard (1978): El show politico: ensayo sobre, y contra, el star-system en política. Barcelona: Dopesa.

Smink, Veronica (2010): “El impacto político de la salud de los presidentes”, BBC Mundo, 19 de agosto. 
Streiffer, R.; Rubel, A.P. y Fagan, J.R. (2006): "Medical privacy and the public's right to vote: what presidential candidates should disclose", Journal of Medicine and Philosophy, vol. 31, n 4, pp. 417-439.

Torbeña, Adolf (2008): Cerebro y poder. Madrid: La Esfera de los Libros.

Treisman, Daniel (1996): “¿Por qué ganó Yeltsin?”, Política Exterior, nº 53, septiembre-octubre, pp. 25-40. 